Fecha de recepción: julio 2021

Fecha de aprobación: agosto 2021

Fecha publicación: septiembre 2021

\section{Biomimetic approach for experimentation and digital fabrication with bio-based material: the lightness and resistance of the Agave Sisalana}

Rodrigo Barbosa de Araújo ${ }^{(1)}$, Amilton José Vieira de Arruda ${ }^{(2)}$, Jorge Lino Alves ${ }^{(3)}$ and

Paulo Carvalho Araújo ${ }^{(4)}$

\begin{abstract}
Bioinspiration in nature's design strategies aligned with digital fabrication, have great relevance for problem solving with a focus on the systematic application of biological information for the emulation of natural elements. Currently, the possibilities are given by the latest technologies, production systems and the development of new structures and materials. This research explores the investigation of biology, the use of parametric computing and digital fabrication, including experiments with sustainable materials as inseparable dimensions of bioinspired design. Agave Sisalana fibers have excellent lightness and resistance properties provided by the structural pattern of cell walls and their material properties. Being presented as a natural system of biomimetic inspiration and bio-inspired material experimentation.
\end{abstract}

Keywords: Biomimicry - Bio inspired - Agave - Parametric Design - Digital Fabrication - Grasshopper - Material Design - Natural fibers - Bio inspired Materials - 3D printing

[Abstracts in spanish and portuguese at page 266]

(1) Rodrigo Barbosa de Araújo. PhD student in Design at the Federal University of Pernambuco (PPGD UFPE). Master in Design (PPGD UFPE). Bachelor of Design from the Federal University of Paraíba (UFPB). He was an assistant professor in the UFPB Design Department. Experience in industrial design, with an emphasis on product design and knowledge in visual programming. Researcher in the research group on Biodesign and Industrial Artifacts - UFPE (BR), working in the lines of research on design and technology, and digital artifacts; Ph.D. international mobility researcher at FEUP (PT), where he develops studies involving biomimetics / bionics, material design and digital manufacturing processes.rodrigobarbosadesigner@gmail.com

(2) Amilton José Vieira de Arruda Graduation in Industrial Design Product Project by UFPE (1982), Master in Design and Bionics by IED in Milan (1992), Doctorate in Ricerca in Disegno Industriale - Ph.D by University of Milan Politecnico (2002) and postdoctoral in Design and Bionics at IADE European University UNIDCOM Lisbon (2018/2019). 
Since 1985 professor of the UFPE Design Course. He is currently associate professor IV. He coordinates the Research Group on Biodesign and Industrial Artifacts at UFPE. Organizer together with Edgard Blucher of the [DesignCONTEXTO] series design, culture and technology essays from the following books: (2017) 1. Design and Complexity; (2017) 2. Design and Social Innovation; (2018) 3. Design, Artifacts and Sustainable Systems; (2019) 4. Narratives and Languages in the creative process in Modeling and Prototyping (in press). Always with Edgar Blucher he organizes the series [designNATUREZA] essays on design, bionics and biomimetics with the following book: (2018) Methods and Processes in Bionics and Biomimetics: the technological revolution by nature. With the publisher Insigh in (2019) we launched the following title: Topics in Design: Biomimetics, Sustainability and New Materials; and recently with Blucher (2020) the Book: Design and Bionics. Carmelo Di Bartolo and Centro Ricerche IED: esperienze memorabili da 30 protagonisti. amilton. arruda@ufpe.br (D) https://orcid.org/0000-0003-4551-4497

(3) Jorge Lino Alves. Mechanical Engineer, PhD in Materials Science (University of Lehigh/USA - 1997), Associated Professor at FEUP (University of Porto/Portugal). Director of the Master Program in Product and Industrial Design (MDIP) at FEUP. Director of DESIGNSTUDIOFEUP. Director of the Product and Services Development Laboratory, Member of the Department Council of DEMec, Member of the Scientific Committee of MIETE and Member of the Coordinating Council of CEMUP (2003-). President of the Portuguese Society of Materials (SPM) (2019-21). Coordinator of the Technical Division of Structural Materials at SPM and Director of SPM Materials Science and Technology Magazine (2019-). He was Vice-President of INEGI (2002-2010), Member of the College of Mechanical Engineering (North Region) of the "Ordem dos Engenheiros" (2007-2010), Coordinator of the INEGI Bulletin (2002-09). He is a member of the Technical-Scientific Council of Tecnometal Magazine. Develops research in the area of product development, additive manufacturing, conversion processes and rapid tool manufacturing, ceramics, mechanical behavior and relationship with the microstructure. Supervised more than 100 dissertations, co-authored 1 book on Additive Manufacturing (2001), two on Mechanical Construction Materials $(2013,2017)$ and one on Advanced Materials (2007). He is author of more than 200 articles in magazines and book chapters, and has 22 prizes in contests. Associate Professor at the Department of Mechanical Engineering, Faculty of Engineering, University of Porto. R\&D areas: Additive manufacturing (3D printing) and prototype conversion technologies and rapid tool manufacturing, ceramics applied in the casting area, mechanical behavior and relationship with the microstructure, and product development. He was Vice President of INEGI in the period 2002-2008. Member of the Coordinating Council of CEMUP in the period 2003-2014 and 2016 - 2019. Member of the College of Mechanical Engineering of the Northern Region of the Order of Engineers in the 2007-2010 triennium. Vice-Coordinator of the Research and Development Unit "New Technologies and Advanced Production Processes", FCT, INEGI, 1999-2012 and coordinator since 2012. He is director of the Product and Services Development Laboratory from DEMec / FEUP, 3D printing area, since 2015. Director of Design Studio FEUP, since 2015. Member of the Coordinating Council of DEMec, since 2014, member of the Scientific Council of MIET of FEUP, since 2014. Deputy Director of the Master's Course 
in Industrial and Product Design, since 2013. Belongs to the Technical-Scientific Council of Tecnometal Magazine since November 6, 2018. He was Vice President of SPM in the 2017-2019 biennium. falves@fe.up.pt

(4) Paulo Carvalho Araújo. Architect, Master in Design at UFPE, specialist in computational methods of design and digital fabrication, accumulates knowledge in the areas of parametric design, generative and biodigital design. Founding CEO of SELVAGEN, Startup that combines nature and technology in the development of Design and Architecture artifacts, is a consultant for Design and Innovation at Porto Digital, in addition to teaching courses and lectures at renowned events and institutions.paulodca@gmail.com

\section{Introduction}

This article presents stages of research development for a $\mathrm{PhD}$ thesis in Design in the Postgraduate Program in Design at the Federal University of Pernambuco, Brazil, in partnership with the Faculty of Engineering of the University of Porto, Portugal. The work in progress involves the practice of biomimetic design of structures and bioinspired materials in natural systems, it also involves parametric design technologies and digital fabrication. This investigation is within the scope of design, innovation, transdisciplinarity and design relationships with nature, biology and technology.

Various activities are developed, from bibliographic reviews in order to adapt the theoretical framework to the development of the investigation. Constant search for scientific articles, books, technical materials. Research of used equipment. Methods of optical microscopy and scanning and material manipulation.

Bioinspired research for problem solving has focused on the development of methods and tools for the systematic use and application of information on natural elements. The methodological approach in biomimetics aims to study the strategies of nature, having it as a principle and inspiration for solving design problems. Biological research favors ecological performance and allows the definition of metrics on the creation of forms and bioinspired materials (Baumeister, 2014; Benyus, 2003). The possibilities are given by the latest technologies, production systems and the development of new structures and materials.

Innovative ideas have emerged from research on systems and natural properties that do not always translate only in appearance and aesthetics, but that the natural shape also favors the gain in efficiency (Soares \& Arruda, 2018). Biomimetics aims to fill this gap by increasing the dimensionality of the design space through the emulation of strategies for bioinspired structures, materials and bioinspired additive manufacturing. This holistic view considers the investigation of biology, parametric computing and the manufacture of materials as inseparable dimensions of design, resulting in ecological artifacts from the beginning (Oxman, 2015).

The main developments in solutions for structures and materials inspired by biology are mainly related to the physical and mechanical properties of the material or, alternatively, 
to the structural characteristics of the material or structure built with the material. This approach is successful when the function is related to the characteristics of the biological structure and also to the properties of the biological material (Byrne et al., 2018).

The area of material design as a demand from science and technology to innovation with the advancement of knowledge in the science and technology of materials has made it possible to manipulate and create new materials with better properties to meet specific applications and biomimetics has contributed strongly for sustainable solutions (Byrne et al., 2018). With the advent of additive manufacturing technologies and the design of new materials for $3 \mathrm{D}$ printing, the possibilities for the emergence of new composite materials with different properties and possibilities for innovation in sustainability have constantly increased (Daya, 2017).

According to Tedeschi (2014), everything is formed by structures. This knowledge influenced the methods of construction, the use of materials and the way artifacts are manufactured with the advent of parametric design strategies. Grasshopper understands a new language of form, a manipulable interpretation of complex geometries. The author points out that although initially they provide a skillful interpretation of organic geometries, they often do not have information that reflects the manufacture or even the material with which it is made.

Building objects must have a material or dynamic relationship with the forces that involve the material in the form and the structure and should not be considered in isolation, leaving the material solution independent of the form (Tedeschi, 2014). The investigation of Voronoi chart diagrams is motivated by many applications and structural problems that can be easily solved with their help. Cellular structures of biomaterials are of interest to scientists. Cellular materials offer a high resistance to weight ratio, high rigidity, high permeability, excellent impact absorption and thermal and acoustic insulation (Damodaram, 2018).

Light cellular composites, composed of an interconnected network of solid walls that form the edges or faces of cells are an emerging class of high-performance structural materials that can find potential application (Damodaram, 2018). The natural system of the cellular structure of Agave has such potentials, it is referred to as an object of bioinspired study. In this line, the steps are briefly described during the development stages.

\section{Biomimicry}

Design strategies inspired by nature are based on a significant proportion of the theory of 'learning from nature' and consider nature as the paradigm of sustainability. Several terms are use interchangeably in the literature for different ways of "learning from nature", including Biomimicry, Biomimetics, Bioinspired Design and Bionics (Bhushan, 2009; Vincent, 2009).

According to Pauw (2015), when the design emphasis focuses on finding (environmentally) sustainable solutions, "Biomimetics" is the most common term (Reap et al., 2005; Vincet, 2009). In summary, biomimicry refers to a design strategy aimed at generating sustainable solutions. 
The degree to which designers emulate the lessons of nature can vary from simple, sometimes superficial analogies, to in-depth studies of natural, material forms, functions, processes, and systems (Soares \& Arruda, 2018). According to Pauw (2015), the knowledge of strategies of natural systems allows implementations in a systematic way in the practice of the design process. Through biomimicry we are learning to emulate natural forms, processes and ecosystems and bioinspired materials to create more sustainable projects.

According to Baumeister, (2014) and Benyus, (2013) the emulation of these more refined projects for the planet can help humans move towards technologies that consume less energy, reduce the use of materials, reject toxins and work as a system to create favorable conditions for life. According to Muller (2018), bioinspiration using insights into the role of biological systems for the development of new engineering concepts has already established itself as a successful and rapidly growing field of science. The possibilities are given by the latest technologies, that is, production systems and the development of new structures and materials.

\section{Biomimicry Thinking methodological approach}

An approach called Biology to Design (Biomimicry Thinking) was used, following the phases according to the need of the project when the process is configured from a biological inspiration and seeks to provide a direction for the development of some project or artifact and/or material bioinspired (Baumeister, 2014) (See Figure 1).

Other methodological approaches were also incorporated into the design process, such as parametric design as a method of emulating the strategies of the natural system, digital fabrication and material experimentation as auxiliary means of supporting the practical execution of the research.

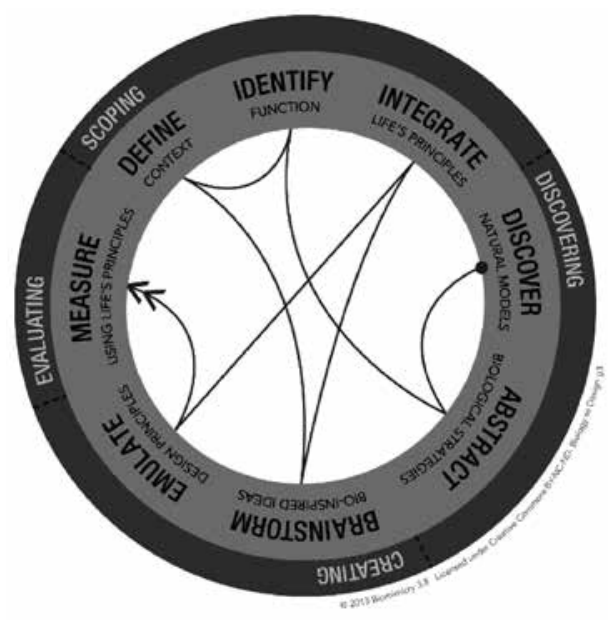

Figure 1. Biology to Design (Biomimicry Thinking), Design Lens (Baumeister, 2014). 


\section{Natural fibers: Agave Sisalana}

Natural fibers have been used to make ropes, fabrics and shelters for thousands of years. Vegetable fibers are based on cellulose and are found in the stem (liber), leaves, seeds and fruits. Many are derived from fast-growing plants, making them potentially renewable. Its properties are compared with those of man-made fibers (Ashby \& Johnson, 2011).

Due to the fact that natural fibers have low densities, their specific properties are much more attractive. This has led to efforts to use them as reinforcement for various artifacts. The sisal fiber is derived from an agave species, Agave Sisalana. Among many lignocellulosic fibers that have been gaining space, the Agave Sisalana, produced in the Northeast of Brazil, stands out, which presents technical, economic and environmental advantages (Carneiro, 2017).

Not only for environmental reasons, but for technical and economic reasons, vegetable fibers have been gaining ground in the industry. It is valued due to its resistance, durability, ability to stretch, the affinity for certain dyes, and, like coconut fiber, it is resistant to degradation in salt water. Sisal is also used as a reinforcement in polymeric matrix composites (Ashby \& Johnson, 2011).

It has extreme value, mainly due to its excellent mechanical properties, presenting mechanical behavior similar to synthetic fibers in relation to the traction force (Carneiro, 2017). From an anatomical point of view, sisal fibers are structural cells whose function is to support and stiffen the leaves and stem. Thus, when compared to other natural fibers, Sisal fibers have superior strength, in addition to having good durability (Sapuan, 2006). As the fibers come from the leaves, and are also present in the plant's pseudostem, its chemical constitution is basically formed by the same compounds present in the leaves, having in its chemical composition cellulose, hemicellulose, lignin, pectin and waxes (Araújo, 2015, Mwaikambo \& Ansell, 2002; Martin et al., 2009).

In addition, the floral scent of the plant has strategies of lightness and resistance, these functions are provided by the combination of structural characteristics and material properties. The study and emulation of the shape of the structure and function of cell walls together with the possibilities of developing a bioinspired material is the focus of investigation in this article. The study of the cellular structure of Agave, which presents lightness and resistance strategies and the materials that make up the fiber walls and their mechanical properties, have potential for biomimetic application for light structures and bioinspired material.

According to Gleich, et al. (2002), the microscopic dimension allows the observation of the structures of nature at levels of advanced detail. A recurrent example is represented by the plant cell anatomy of plants in general, which reveals compact bundles of differentiated cells and cells. The geometric arrangement and compacted integration produces a complex, strong, but flexible structure. All cells have a structural role in addition to other functions. Figure 2 with SEM images of Agave Sisalana shows such a geometric arrangement. According to Taiz \& Zeiger (2004) the functions of plant systems depend on structures, on the structural shape of different tissues, such as, for example, mechanical properties, etc. They can have different shapes -cylindrical or spherical- but in general, they are multifaceted isodiametric cells. It has multiple faces, that is, many sides having approximately the 

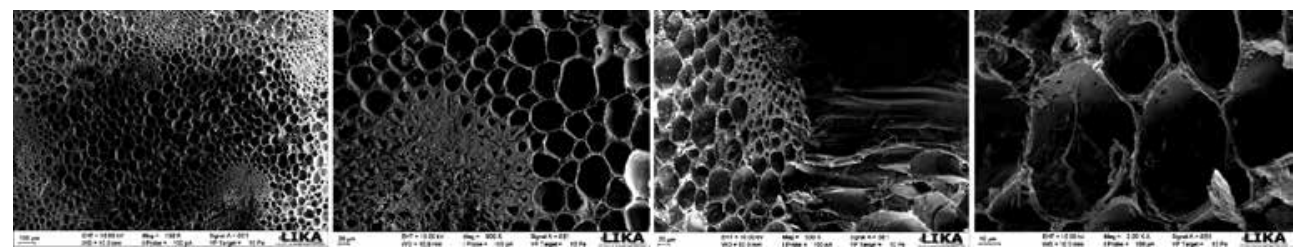

Figure 2. Scanning electron microscopy of Agave Sisalana fibers. Produced by LIKA - UFPE. Source: Authors (2019).

same dimensions. The cell wall that delimits a cell can also vary in thickness, ornamentation and frequency of stitches, etc. Despite this morphological diversity, cell walls are commonly classified into two main types, primary and secondary. The primary cell walls are typically thin. The secondary cell walls are thicker and more resistant than the primary ones, the xylem cells, such as those found in wood, are notable for having highly thickened secondary walls, reinforced by lignin.

\section{Bioinspired structures}

Cellular structures of biomaterials are of interest to scientists. Cellular materials offer a high strength- to-weight ratio, high rigidity, high permeability, excellent impact absorption and thermal and acoustic insulation. Light cellular composites, composed of an interconnected network of structures that form the edges or the face of cells, are an emerging class of high-performance structural materials that can have potential applications. Weight and rigidity, flexibility are key factors in the development of materials and artifacts for different sectors. Light cell structures are widely used for this reason (Damodaram, 2018). The natural systems of cellular biological structures have a wide range of lightness and resistance strategies, such as the Agave Sisalana plant (Araújo, 2015). Thus, bioinspired materials and structures that result in desirable material characteristics are a significant inspiration for projected cellular structures.

Cohen \& Reich, (2016) points to a basic principle of patterns of tubular structures present in nature. Such structures are characterized by a hollow cylinder, rod or tube. The authors describe that the hollow cylinder provides stability against bending and deformation and is adjusted to resist bending in all directions. In the case of repeated tube structures, each tube in the arrangement works as a single tube, distributing the stresses throughout the structure, optimizing resistance to mechanical stresses. This design and research approach has been developed by many researchers.

Damodaram (2018) developed a study of biomimetic design with composite materials reinforced by $3 \mathrm{D}$ printed staple fibers of light structures, but structurally safe, sustainable under different loading conditions, and resource efficient. The author designed cell struc- 
tures with strength properties, taking into account weight and rigidity factors, combining multifunctional properties together with light and material characteristics. Currently, these bioinspired structures and materials with high resistance and weight are widely applied in many fields of design, architecture, among others, with the aid of parametric design and digital fabrication.

\section{Parametric design}

Parametrism has its origin in parametric design, aims to organize and articulate the growing diversity and complexity of natural systems. It implies that all elements of design and architecture artifacts are parametrically manipulable. This implies a fundamental ontological change in the basic elements and constituents of the project. It is not limited to the use of rigid geometric figures- rectangles, cubes, cylinders, pyramids and spheresparametrism the shapes are geometric entities, geometric building blocks fundamental to dynamic, organic systems that can react to 'attractors', and be made to interact with each other through scripts. The objective is to form a varied and complex structural order, using scripts to differentiate and relate all the elements and subsystems of a project (Schumacher, 2010).

Aspects of parametrism have been used in industrial design, architectural design, interior design and urbanism. It is based on the constraints of a parametric equation and allows to perform emulations of natural systems for design purposes. One of the determining characteristics is that parametrism implies that all elements of the project become parametrically variable and mutually adaptable, through computers, algorithm programs and computational geometry.

Computational geometry is concerned with the design and analysis of algorithms for geometric problems. In addition, other areas of computer science that are more oriented towards design practice give rise to problems that are inherently geometric. This is one of the reasons why computational geometry arouses great research interest as it is a well-established area (Aurenhammer, 1991).

According to Rattes (2015), parametric design is still more widespread in architectural projects than in product design, however it takes on greater proportions in this area every day. With it, CAD software is used to work with generative algorithms and by means of parameters, be they of any order, but that are grounded, as they help groups of designers and architects to use computing as a process, and no longer a mere representation of the final object. The meaning of the project can be profoundly changed, according to the entities (parameters) that complete the complexity of the project.

This generation of shapes and structures by means of parameters, facilitate and accelerate the creation process, as they allow the transposition of the geometry of nature to the computational environment (CAD), helping in the realization of analogies between the natural system and design. In addition to being faithfully adapted to the context of complexity, due to the fact of conceiving complex shapes (natural system) and the ability to be adjustable by parameters, according to the need or conditions (Rattes, 2015). 


\section{Grasshopper}

According to Akos, et al (2014) Grasshopper is a "visual programming" editor in the form of a plug-in integrated with Rhino3D developed by Robert McNeel \& Associados. It has a versatile modeling environment used by creative professionals in a diverse range of fields, including architecture, engineering, product design, among others. In parallel, Grasshopper and Rhino offer the opportunity to define precise control of parametric models, to explore generative design workflows, and to develop high-level programming logic - all within an intuitive graphical interface.

It is a visual programming language that works with different types of objects, parameters and components. It works with the concept of input and output: Input can be translated as "data entry". Grasshopper objects require input data, there are blocks that allow undefined data inputs that can be established by the project's needs. Output can be translated as "data output". Once the input data and the object have been established, the object will, in turn, establish the output data. The output data is directly related to the action represented by the object (Akos, et al. 2014) .

The parameters are boxes that normally have input and output, store data - numbers, colors, geometry, etc. Geometry parameters can reference geometry from Rhino, or inherit geometry from other Grasshopper components. Input parameters are dynamic interface objects that allow you to interact with your definition. The number slider, represents a number that can be defined by the user from a domain. The components perform actions based on the input data they receive. There are many types of components for different tasks (Akos, et al 2014). Each component can be considered as a module because it carries a schedule that has a specific result (See Figure 3, 4 and 5).

"Sliding" objects control geometry in a natural and intuitive way, the connection that is made between this input object and what is visualized in Rhino is instantaneous. One of the benefits of using Grasshopper is that the geometry visualization is a light representation of the solution that is updated automatically (Akos, et al., 2014).

\section{Voronoi}

According to Aurenhammer (1991) one of the most fundamental data structures in computational geometry is the Voronoi diagram. The Voronoi diagram has practical applications in different fields, from mathematics, physics, architecture, design and in the field of the arts, arousing his fascination for its intrinsic aesthetics. Thanks to the development of digital tools used in the design process, the Voronoi diagram is an example of the main trends in architectural design, allowing, for example, to describe a system of self-organization of biological structures through digital means (Nowak, 2015) . 

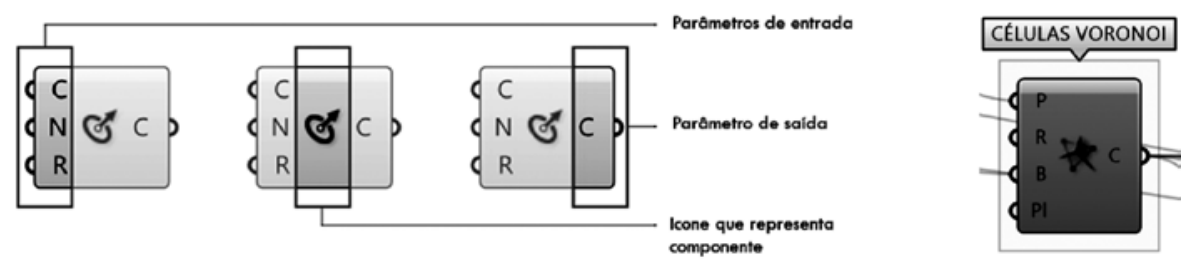

3

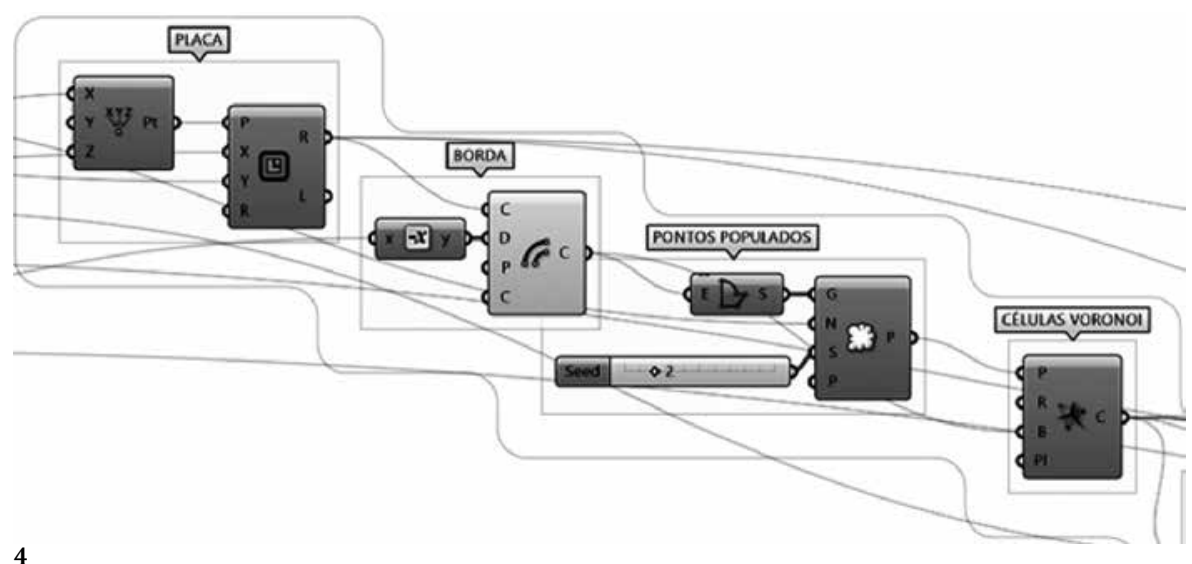

4

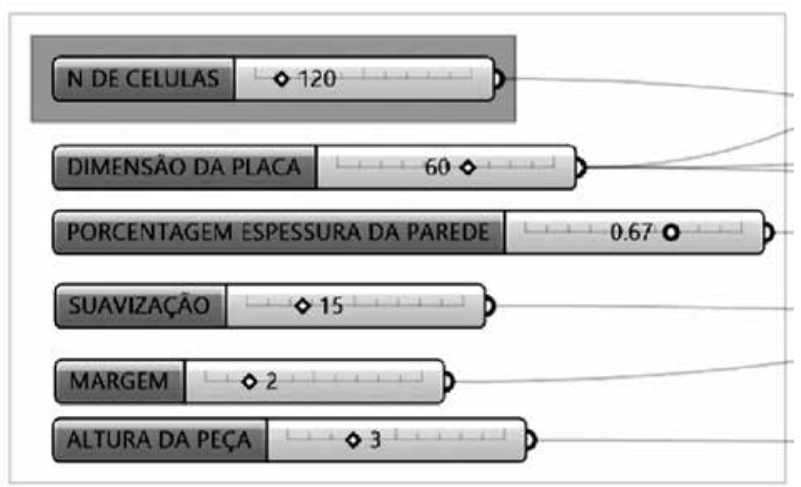

5

Figure 3. Voronoi function component/parameter input boxes. Source: Authors (2021). Figure 4. Example of the component interface in Grasshopper Source: Authors (2021). Figure 5. Parameter box of the Agave parametric design strategy. Source: Authors (2021). 
Modern design methods increasingly depend on understanding the nature of the processes and principles of self-organization of biological structures and their representation using mathematical models that can be applied in technology and digital fabrication. As a result, the elements of bionic design play a more significant role in shaping contemporary architecture and design. The development of computer technology has made it possible to create more complex and complicated structures and surfaces inspired by natural shapes (Nowak, 2015).

Voronoi diagrams are an associated set of regions around points on the Euclidean plane. Among several mathematical definitions and diverse applications, they are also used in computer graphics to generate some types of organic textures. According to Tedeschi (2014) the Voronoi diagram is a decomposition of a metric space according to proximity criteria. Given some number of points on the plane, his Voronoi diagram divides the plane according to the nearest neighbor.

For Nowak (2015), the inspiration for the discretization of a surface or structure, that is, transforming a distribution of continuous functions into individual units, using the Voronoi diagram is increasingly applied in the modeling of bioinspired artifacts. As a mathematical problem, the division of space fascinates scientists and researchers. Consequently, designers use Voronoi's space cells also in modeling structural or spatial shapes and as patterns applied to projects.

The use of mathematical models represents the structure and organization of the forms found in nature, being increasingly used in multidisciplinary projects. The design of structures and elements in both architecture and design using computational geometry methods creates new opportunities for projects through Voronoi's tessellation.

According to Nowak (2015), the Voronoi diagram is a graph that consists of cells created from cells, the edges and nodes of the Voronoi diagram (an equidistant point of at least three centers. The Voronoi diagram is made up of segments and half-lines that form the edges of the Voronoi areas for each of the centers. The Voronoi area is defined for each center as a set of points on the plain that are closest to a given center.

Thanks to the development of digital tools used in the design process, Voronoi diagrams are used in modern architecture and in product design, a multitude of computer programs allows (for example, Grasshopper) for a wide spectrum of modeling possibilities, in innovative search for new ways of creating algorithms to build ideal structures. The modeling of architectural and structural forms based on Voronoi diagrams is one of the most important trends in the investigation of new forms of expression in architectural design (See Figure 6).

Voronoi diagrams can also be used to transform a continuous distribution of individual cell units into spatial or structural shapes, leading to the creation of $3 \mathrm{D}$ structures. As a result, it is possible to create objects with a natural and remarkable design inspired by the shapes found in nature or by applying natural systems of self-organization of biological structures in classic geometric shapes. Consequently, algorithms that simulate natural formation processes are increasingly used in the field, modeling the principles of Voronoi diagrams.

Examples of application of the voronoi diagram (See Figure $7^{\star}$ ) 

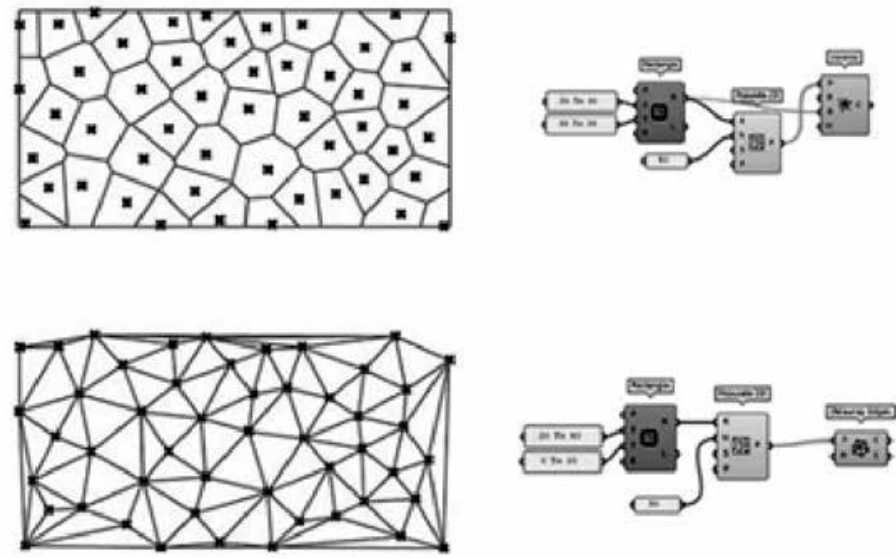

6

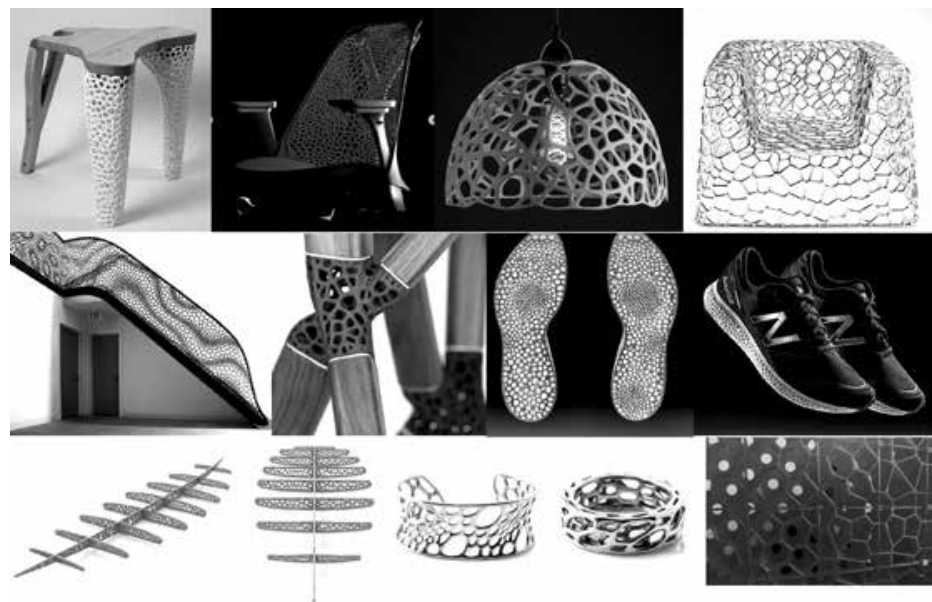

7

Figure 6. The simplest among the algorithms that make up the Voronoi diagram is the Delaunay triangulation. The drawing is composed of triangles and circles connecting all the points in a set of points in three. Although it seems random, there is only one result for each set of points. Source: https:// www.instagram.com/p/CNGA5DwBIMb (2021). Figure 7. Examples of artifacts with application of the computationally generated voronoi pattern. $\left(^{\star}\right)$ The images were taken from the internet and searched on google. Sources: https://dantesebastianreulink.com;behance.net/mattbarnum; https://twitter.com/3d_ eric/status/1348704571074482177; https://cs.nga.gov.au/detail.cfm?irn=274663; https://n-e-r-v-o-u-s. com/index.php; (2021); Rael \& Fratello (2018). 


\section{Digital fabrication}

The link between design and manufacturing has always been crucial for architecture and industrial design. New manufacturing techniques, assembly processes and materials often cause paradigm shifts in the project. Before the digital revolution, the designer managed the complexity of the projects by dividing the components into individual parts and studying assembly strategies from part to all using scale models and drawings. This process was limited to orthogonal structures and did not have the capacity to respond to complex shapes. The digital revolution released this restriction by integrating the output of design directly into manufacturing (Tedeschi, 2014).

The first stage of the digital revolution focused on project control through the generation of digital three-dimensional models. Since construction processes are interpreted directly from 3D geometry, they lead to the creation of 3D structures. The ambition to directly translate an idea into reality is already possible for objects or components of different scales. In other words, it is possible to create a physical object from a $3 \mathrm{D}$ virtual model using rapid prototyping, which is an additive manufacturing technique in which the material is deposited in layers to print a component (Tedeschi, 2014).

In this sense, Damodaram (2018), exemplifies that for low volume manufacturing, highly complex parts, fully assembled components, customized parts or time sensitive parts, the use of a professional 3D printer is the best choice. You must choose the printing method, material properties, surface finish and complexity of the piece most appropriate to the specific objective, at a given time in a digital manufacturing project.

\section{Material design and 3D printing}

Although mankind has performed the tasks of manipulating materials, then transforming them into artifacts. 3D printing interrupted the idea of craftsmanship and introduced a deviation in the material lineage of transforming the small into a large one. 3D printing is directly linked to traditional techniques of building and making things. However, using computer aided design (CAD) and computer aided manufacturing processes (CAM). Manufacturing and digital fabrication fill the great gap that exists between non-industrial, industrial and digital modes of production, expanding the benefits of each one (Rael \& Fratello, 2018).

The computer and the $3 \mathrm{D}$ printer allowed us to emulate strategies of nature using data to explore structures of material systems and transform natural materials, for example, fibers and particles into personalized objects and bio-inspired products that serve as new building blocks for the future, using materials that are locally available, inexpensive, and derived from sustainable sources or waste streams.

Rael \& Fratello (2018) points to the challenge of limited sources available for additive manufacturing materials, suggesting new bioinspired possibilities for digital materiality. The digital aspects have potential not only for the transformation of materials, but also the design of the materials themselves. The nature of these materials - which can be man- 
ufactured locally, comes from recycled sources; by-products of industrial manufacture (natural fibers, nut shells, coffee grounds, grape shells) - can place them in the realm of natural construction and manufacturing materials. However, the expansive and nascent potential of these traditional materials, when coupled with additive manufacturing, offers unconventional possibilities, such as the possibility of developing targeted structural capacities (Rael \& Fratello, 2018).

Still according to the authors, considering the particle and the part, and their inherent possibilities is not the only way that we conceive the expansion of additive manufacturing. An advantage is the possibility of printing smaller pieces to create larger objects. However, $3 \mathrm{D}$ printers generally do not complete their tasks on their own, it is a trial and error process that usually requires several initiations to complete a print job.

The beauty of a 3D printed structure built is that each part can be individually adjusted to respond to geometric particularities in a complex way. In addition, 3D printing is a potentially sustainable manufacturing method. It can take advantage of local and ecological material resources and serve as a vehicle for upcycling, producing very little waste compared to subtractive production methods.

\section{Why use composite materials?}

The biggest advantage of modern composite materials is that they are light and resistant. By choosing an appropriate combination of matrix and reinforcement material, a new material can be made to exactly meet the requirements of an application. The compounds also provide design flexibility because many of them can be shaped into complex shapes (Damodaran, 2018).

According to Callister (2000), in order to obtain unusual properties, science and technology together with the engineering of materials, developed combinations of individual materials, aimed at meeting diverse properties through the joining of two or more different materials in one the only material that is now called composite. According to the author, most composite materials consist of only two phases. The characteristics of composites are a function of the properties of the constituent phases, their relative quantities and the geometry of the dispersed phase. The $1^{\text {st }}$ matrix phase is continuous and involves the other phase; The 2nd dispersed phase, which in the context, "dispersed phase geometry", implies the configuration of the particles or fibers, size, disposition and their orientation.

The most technologically important composites are those in which the dispersed phase is in the form of fiber. Fiber-reinforced composites are designed and developed with the aim of including strength, high stiffness in relation to their weight, or greater flexibility. Fiber reinforced composites are subclassified according to the fiber length, influence of fiber orientation and concentration. The arrangement or orientation of the fibers in relation to each other, the concentration of the fibers and their distribution have a significant influence on the strength and other properties of fiber- reinforced composites (Callister, 2000). 


\section{Bio-based materials}

Nature has produced many light structural designs, such as bones, bamboo, wood, honeycomb, among countless other examples. Damodaram (2018) considers that bio-inspired materials in nature with optimized cellular structures will have high specific stiffness, or marked flexibility and will lead to light materials. The area of material design as a demand from science and technology to innovation with the advancement of knowledge in the science and technology of materials has made it possible to manipulate and create new materials with better properties to meet specific applications and biomimetics has contributed strongly in this area for sustainable solutions (Muller, 2018).

Sustainability is a strong point in the development of innovations by making direct use of biological material solutions. In fact, biological systems made of biological materials do not create waste or irreversible damage to the ecosystem. They are of great relevance because they enrich and sustain the ecosystem where they operate. In addition, biological structures provide a wide range of properties with minimal use and flow of materials and energy, and generate fully recyclable products (Byrne, et al. 2018).

Perhaps building materials in the form of particles or fibers, for example, come from a subtractive process of cutting and sanding wood, reducing trees to sawdust, composed of tiny particles. To a large extent, it is a by-product generated by the wood industry in sawmills and furniture factories and on construction sites that can be reused or recycled into fiber-reinforced composites, such as the development of 3D printing filaments (Rael \& Fratello, 2018 ).

According to the authors, 3D printing with sawdust has some similarities to the manufacture of wood products, but in many ways it is also quite different. For Rael \& Fratello (2018), sawdust is not the only material that can be used to print wood-like objects in 3D. Nut shells, shells and seeds are all agricultural by-products that can be ground into fine powders and flours and used to make $3 \mathrm{D}$ printed objects with similar colors and properties. Bioinspired parametric computing also allows, for example, digital modeling that can simulate the natural grain of wood. In the Poroso project (Figure 8) presented by Rael \& Fratello (2018) A canvas composed of individual wooden components printed in 3D that are fixed together to form a wrapper and a surface with variable dimensions. Its porous pattern is inspired by the vessels found in the microscopic analysis of the anatomy of hardwoods, as if the wood wanted to return to its original state and express its internal growth. When viewed from the final fiber, these vases demonstrate the porosity of the wood. In a living tree, they serve as ducts inside the trunk, a system for transporting water and sap. On the sawdust screen, the pots serve as an opportunity for visual porosity. The subtle curvature of each vase accentuates the openings as convex or concave openings, making the canvas a visual and tactile experience (Rael \& Fratello, 2018).

Within this perspective, the authors make it evident that 3D printing with sawdust and other agricultural by-products has the potential to transform an inherently subtractive process - which begins with trees and ends with dust - into an additive process that transforms this widely available material into components of the design and architecture. 3D printing product of wood, exploring possible shapes and dimensions with wood residue as an emerging material in additive manufacturing. Other projects are also presented by 

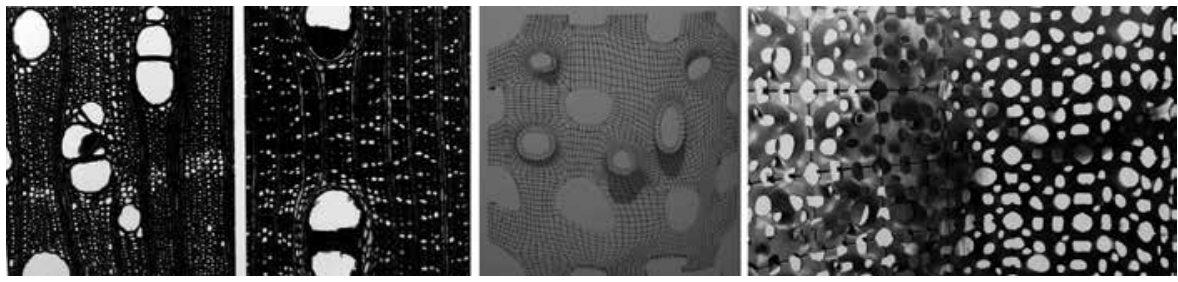

Figure 8. Porous Project, 3D printing with bio-based materials, bioinspired in the veins of the wood. Source: Rael \& Fratello (2018).

Rael \& Fratello (2018), such as Wood Block, designed by Anthony Giannini, which uses 3D printed cellulose powder as a building material that can be mass customized.

In this way, bio-utilization (use of biological raw material) is feasible, as long as it favors the construction of an objective aiming at the sustainability of the project, adapting to local realities and presenting benefits (or harm reduction) to the ecosystem in its use, in an effort to meet certain biologically inspired principles. This approach is successful when the function is related to the characteristics of the biological structure and also to the properties of the biological material (Byrne et al., 2018).

The biomimetic investigation of the properties of agave fibers with application in digital fabrication presents potentialities for emulating a bioinspired material in lightness and resistance strategies, to be used as an input for 3D printers, and also has biodegradation conditions.

\section{PLA}

Polylactic acid (PLA) is a bioplastic; one of the most widely produced biodegradable plastics. According to Ashby \& Johnson (2011), PLA is a thermoplastic derived mainly from renewable resources annually. This bioplastic is a synthetic material made from organic polymers, according to Rael \& Fratello (2018), it is composed mainly of carbon, oxygen and hydrogen, derived from corn starch, cassava roots, sugar cane, among others.

A bacterium is used to obtain lactic acid from these starches and then this material is polymerized. In the production process, bacteria produce lactic acid through the fermentation process of starchy vegetables, such as beets, corn and manioc, that is, it is made using renewable sources (Ashby \& Johnson, 2011; Rael \& Fratello, 2018).

The authors claim that plastics should naturally degrade at the end of their useful life and not cause adverse effects on the environment, argue that the use of cellulose-based materials is an important solution for the creation of plastics and composites with low environmental impact. 
Despite being 100\% biodegradable plastic (if ideal conditions are available), at the end of life, PLA can be recycled, but it is more often successful in situations where industrial composting may be an option for the end of life. Therefore, as it degrades or is incinerated, it releases only organic elements into the atmosphere or the soil.

It can decompose in forty-five days in a composting facility. However, in stable environmental conditions, it takes hundreds of years to biodegrade, which means that it is promising as a durable and resistant enough material for diverse applications in design and architecture. The PLA looks like a normal plastic, in addition to being approved for food packaging. It resembles transparent polystyrene, provides good aesthetics (brightness and clarity), but is rigid and brittle. The polymer can be composed to provide a wider range of material properties. It can be processed like most thermoplastics in fibers, films, thermoformed or injection molded, among other possibilities (Rael \& Fratello, 2018).

Like any other thermoplastic, there are many ways to turn this material into artifacts. It can be used for extrusion, for this reason, it is also one of the most common raw materials used in desktop 3D printers today. The recommended molding temperature is $165-170$ C. However, it is also possible to insert natural fibers to improve aspects of strength and increase the load of biological raw material.

According to Rael \& Fratello (2018), in 3D printing with bioplastic, the cellulose-based materials that enter the PLA include an increasing range. It is now possible to print in $3 \mathrm{D}$ with PLA made not only from corn starch, but also from hemp, bamboo and barley. In addition, materials such as coffee, glass and powdered metals can be added to the PLA to give it special properties, including color, strength and brightness, respectively. Dyes can also be added to the PLA filament to offer a wide range of colors that are an integral part of the material. Likewise Agave Sisalana fibers can also be added to form a composite reinforced with lignocellulosic fibers.

It is through the lens of 3D printing technology and parametric and biomimetic design, together with an interest in natural material systems that leverages the interest in exploring this research.

\section{Development}

This document summarizes the activities carried out so far, elucidating the concept for using the voronoi diagram in the design of the parametric strategy of the bioinspired structure in the geometric patterns present in the Agave cells. It is important to note that the use of voronoi was not a mere aesthetic choice, or because it is a widespread graphic representation in the digital environment and in design. The emulation process makes use of the concept of voronoi as a tool that has the ability to simulate Agave cell patterns based on plant anatomy. It aims to develop a biomimetic structure inspired by the configuration of agave lignocellulosic cell walls. For the emulation of biological strategies, in this phase some fundamental concepts regarding the behavior of each cellular structural organization will be analyzed. Therefore, the objective of this item is to offer analytical support to the development of the bioinspired voronoi structure. 


\section{Analysis and emulation}

At this point, visual analysis is carried out on the formal characterization identified. Here is presented the voronoi geometry present in the agave cells, highlighting the differentiation of two main types of cells (See Figure 9): with thin walls; and with thick walls. The cells with thicker walls have the function of creating greater rigidity and mechanical resistance, however the cells with thinner walls are lighter and more flexible.

Based on plant anatomy, the cells of the parenchyma have a larger diameter and thin walls are lighter and more flexible due to the higher concentration of cellulose and lower amounts of lignin. On the other hand, xylem cells with a smaller diameter and thicker cell walls give the cell more rigidity and resistance because it contains higher amounts of lignin, which makes them heavier (Araújo, 2015).

The visual analysis of the microscopies sought to identify the main structural variations. The patterns can present several variations in the density of the cells, in the thickness of the cell wall, and even in the combination of the different types of cells. These can be presented in the following main ways (See Figure 10 left and right):

Uniform distribution: filling cells of the same size, both with thin walls and with thick walls; uniform size of the units; possibility of size / scale variation;

Combined distribution: variation in the areas of application of cell units with different sizes, with thin and thick walls, variation between size and scale.

In the homogeneous distribution, you can see examples of distribution of cell units with the possibility of scaling the magnification scale, and varying the thickness of the cell wall, however the cells in the frames follow a more uniform size, which can generate simulations of:

- Uniform structure composed of smaller cells, with thin cell wall thickness;

- Uniform structure composed of intermediate cells, thin cell wall thickness;

- Uniform structure composed of larger cells and a thicker cell wall.

In the composite distribution (See Figure 10 right) you can see examples of varied distribution:

- Structures composed of the combination of distribution of larger and smaller cells. Cell wall thickness is thin and also thick. The type of density / concentration distribution can be central, with larger cells located at the ends. Possibility of variation in the thickness of cell walls with gradation of magnification.

These are just a few possibilities for parameterizing the cellular structure, taking into account that the patterns can present different combinations, being able to adapt the strategy to different artifacts, applying more lightness or more resistance in the necessary areas of the structure of the final object. And this digital emulation occurs using the concept of a voronoi diagram as a parameterization strategy for Agave patterns. 

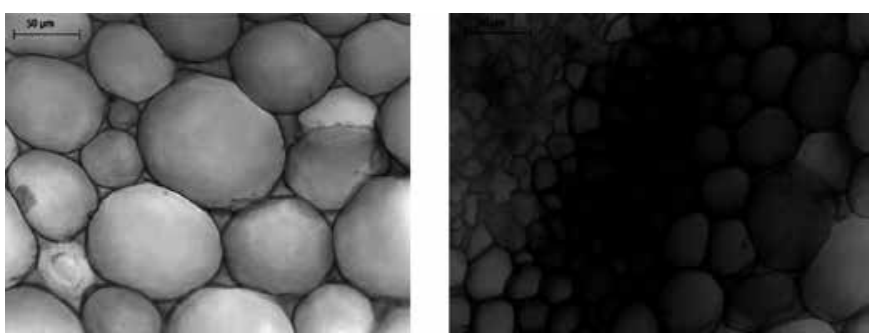

9
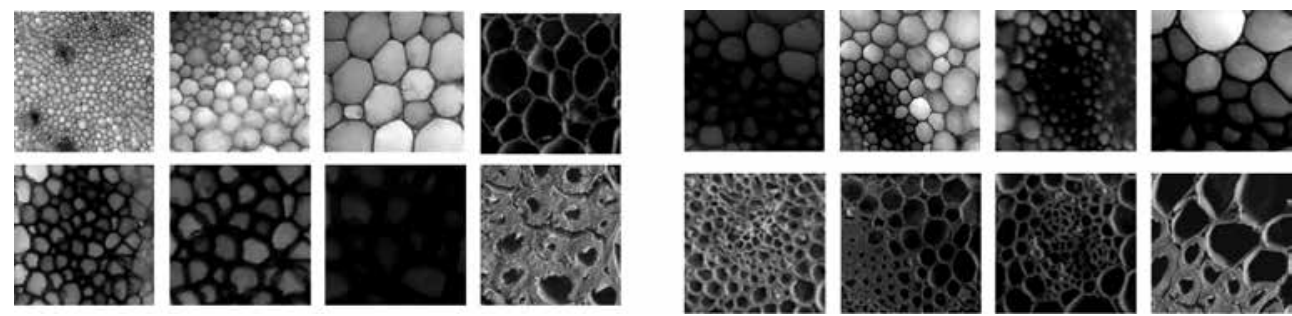

10

Figure 9. Microscopic images of agave. Source: Authors (2015). Figure 10 (left and right). Optical microscopy and scanning electron microscopy images of the agave. Source: Authors, (2015/2019).

\section{Grasshopper parameterization - Bio-inspired lightness and resistance strategy}

The development of this stage was carried out through parametric design and the manipulation of Grasshopper to emulate Agave's lightness and resistance strategies using an algorithm that simulates the natural conformation processes with the Voronoi principles. The resulting shapes are verified in terms of organic structures with an example of emulation of the possibilities of patterns presented.

The voronoi forms cells and cell nuclei represented in the code as points, and from these points the division by the mediatrix is made, between each point a mediatrix is formed, a mediatrix line and when it joins all the mediatrix lines of all points it is formed the voronoi cell. To vary these cells from the pattern there are several methods, one of them using attractors, which is a point to distance or approximate the other cells

Thus, two methods of parametric modeling were applied to emulate structures in the form of Voronoi diagrams, where the first method parameterized the strategy of homogeneous cells with more or less uniform diameters, varying only the density of cells in the structure. The second method was worked to emulate the variations of the cell types in the patterns and to obtain structures with variation of density, variation in the diameter of the cells and thickness of the cell wall. 


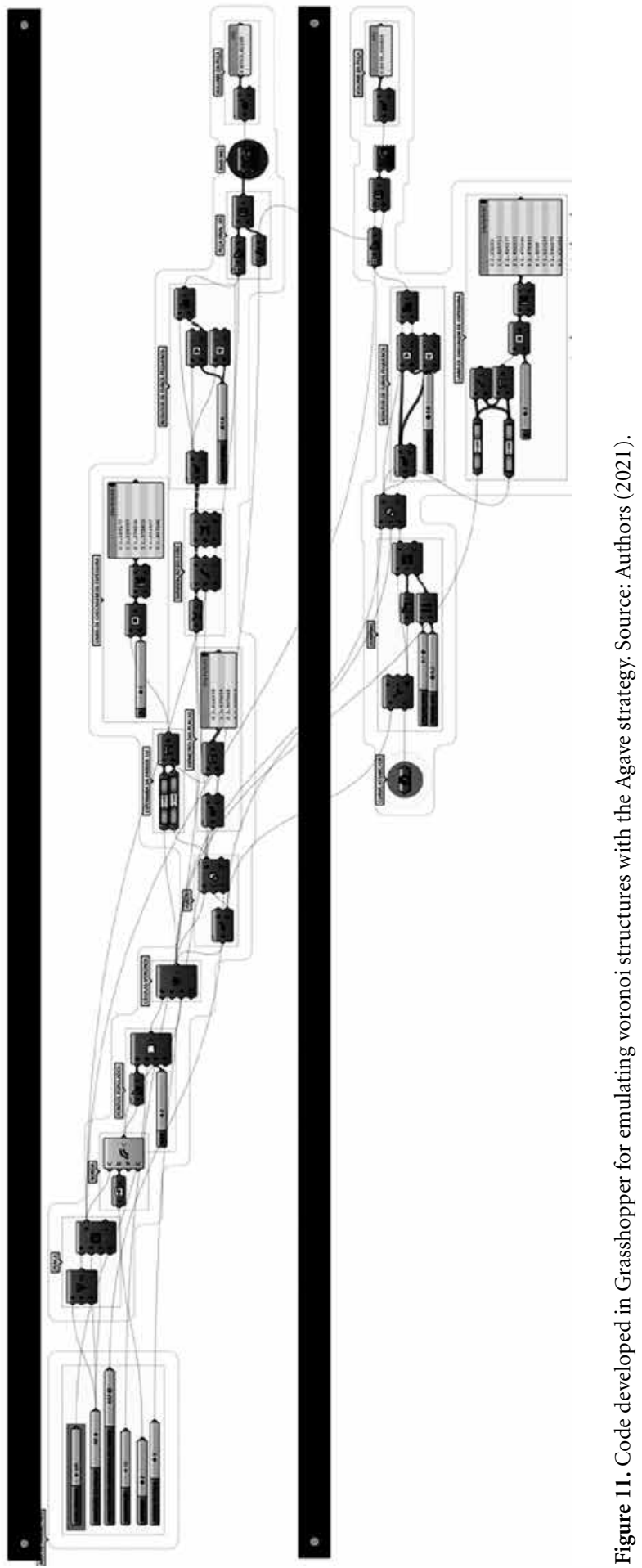



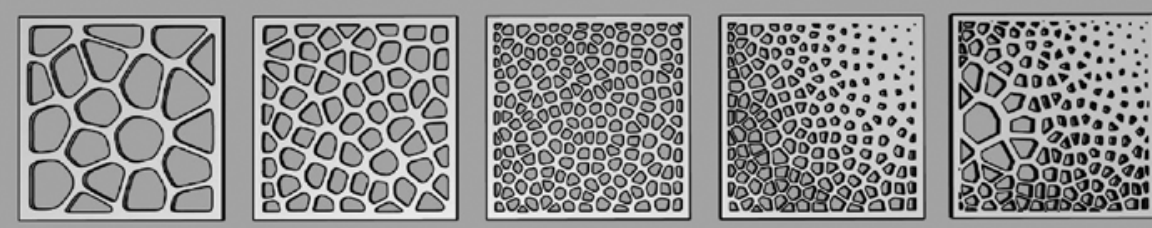

Figure 12. Parametric modeling in the form of voronoi diagrams (Agave cell structure emulation). Source: Authors (2021).

Both techniques presented make use of the same parameters, such as: number of cells; plate size; percentage of wall thickness; smoothing; margin; and height of the piece. Which can be manipulated and generate countless patterns.

Each method has a different technique for creating the patterns. In the first that is more traditional, the pattern is generated from a random division of points, the voronoi is formed from random points, they tend to be cells of the same size, more homogeneous cells, without great variations in the size of the cells. The second method uses attractors, where it is possible to obtain variations, to add tension points where the cells become denser, or further away from the points. Figure 12 shows the parametric structures that can be manipulated by changing the patterns, generating numerous possibilities for structural modeling.

Method one: represents the regular pattern with random distribution of points, which are the nuclei of the cells (referring to the three structures on the left). Method two: irregular distribution of the points, thickening or separating, depending on the attraction function that is done with this attractor.

\section{D printing}

After performing the parametric modeling, the five structures presented were sent to $3 \mathrm{D}$ printing. The goal was to carry out a first three-dimensional materialization so that analyzes and reflections regarding printed structures could be carried out. Being able to compare the volume of the printed areas and the weight of the plates. For this initial analysis, an attempt was made to achieve minimum print thicknesses of the thinnest walls. The plates sent for 3D printing were all printed with the dimensions $6 \times 6 \times 3 \mathrm{~mm}$. During the printing process, there was a need to redesign three models. The areas of the models that need revision (See Figure 13) and redesign (See Figure 14) of the models are highlighted in the sequence 

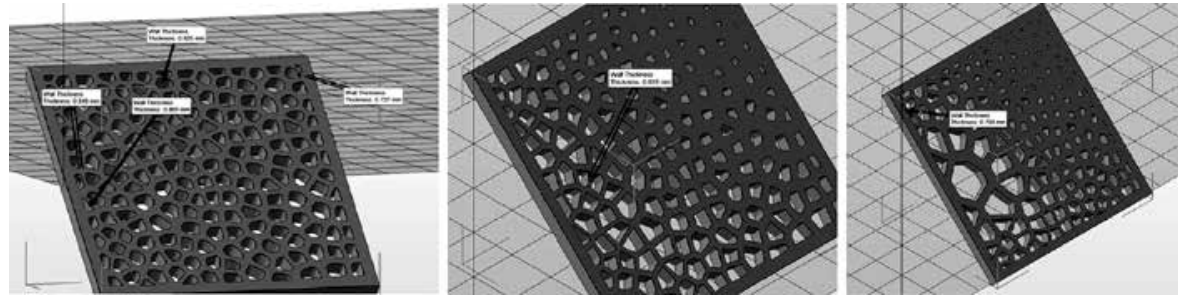

13
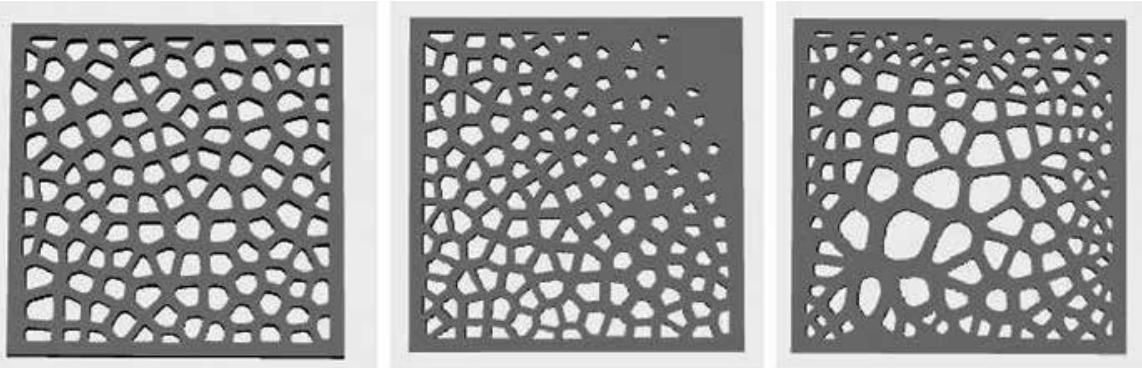

14

Figure 13. Problems identified in the prepress phase, some parts had walls smaller than $1 \mathrm{~mm}$ and needed to be revised. Source: Authors, 2021. Figure 14. Redesign of the models that needed revision. Source: Authors, 2021.

The problems of rejection of the parts occurred due to the presence of too thin walls. The areas highlighted in the image were printable, but there was a risk of breakage in the thinnest parts for the current geometry, and could not support the manufacturing process. In this way, the project was more successful with the redesign of the reinforced areas, leaving them a little thicker. Thus, it was possible to guarantee a successful printing, defining the minimum thickness of $1.0 \mathrm{~mm}$. For larger models, one must always consider the size of the part and reinforcement in the walls that are necessary. However, the minimum guidelines must be suitable for large models. 


\section{Models printing}

The printing of the models was carried out by the process with Selective Laser Sintering powder bed fusion technology (SLS) because it allows higher finishing levels in relation to other processes. SLS Technology, Laser sintering is a 3D printing technique that consists of making an object by melting successive layers of powder to form an object. The process most notably facilitates the creation of complex and interconnected forms (DAMODARA, 2018).

The printing material used in this research stage was a versatile durable nylon plastic that can be used in a wide range of applications, both for prototyping and for industrial quality end products. The printing material was selected by the company that produced the models (Shapeways - www.shapeways.com) with a policy of choosing the first printing material available on its printers in an economical way, where the piece is often printed together with other demands to use the entire area of the printing platform, saving energy and materials time. This material when it is thin, it is flexible enough for hinges and springs and when thick, it is strong enough for structural components. It has a matte finish with a slightly rough surface. This finish removes some material to create a smoother surface. The data obtained with the printing of the models are shown below (See Table 1).

\begin{tabular}{|l|l|l|l|l|l|}
\hline Model & \multicolumn{1}{|c|}{$\mathbf{0 1}$} & $\mathbf{0 2}$ & $\mathbf{0 3}$ & $\mathbf{0 4}$ & \multicolumn{1}{|c|}{$\mathbf{0 5}$} \\
\hline Model volume & $4,33 \mathrm{~cm}^{3}$ & $5,77 \mathrm{~cm}^{3}$ & $6,78 \mathrm{~cm}^{3}$ & $8,06 \mathrm{~cm}^{3}$ & $7,44 \mathrm{~cm}^{3}$ \\
\hline Model Volume Boundary & $\begin{array}{l}10,79 \\
\mathrm{~cm}^{3}\end{array}$ & $\begin{array}{l}10,79 \\
\mathrm{~cm}^{3}\end{array}$ & $\begin{array}{l}10,79 \\
\mathrm{~cm}^{3}\end{array}$ & $\begin{array}{l}10,79 \\
\mathrm{~cm}^{3}\end{array}$ & $\begin{array}{l}10,79 \\
\mathrm{~cm}^{3}\end{array}$ \\
\hline Weight & $4,18 \mathrm{~g}$ & $5,52 \mathrm{~g}$ & $6,25 \mathrm{~g}$ & $8,11 \mathrm{~g}$ & $7,19 \mathrm{~g}$ \\
\hline
\end{tabular}

Table 1. Data from 3D printing models. Source: Authors, (2021).

Through a reflection on the analysis of the data obtained from the impressions of the models, it was possible to observe factors that reinforce the motivation for investigating Agave's lightness and resistance strategies. Based on the literature on plant anatomy and on the analysis and reflections on the cellular structure of agave fibers, according to Araújo (2015), it was evident that the same logic observed in the natural system, applies to the study of the bioinspired parametric structures emulated through the diagrams of voronoi. 


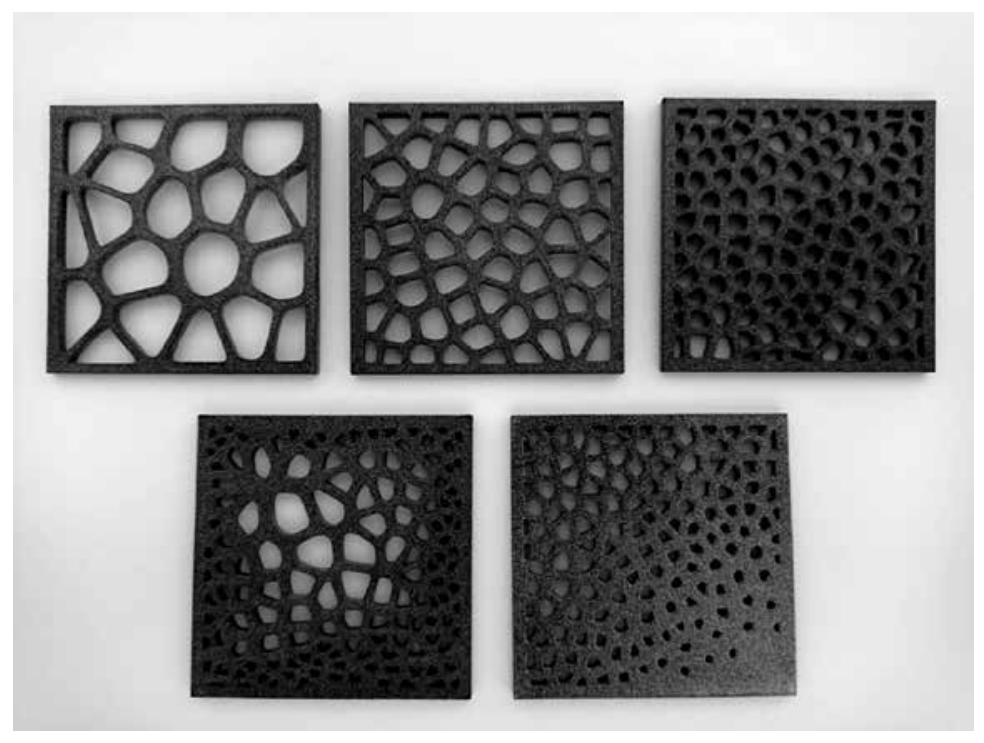

Figure 15 (top and bottom). Photo of the models printed in 3D. Source: Authors, (2021).

- Models 01, 02 and 03 (See Figure 15 above) have a uniform distribution pattern. Comparing the data of the three models and performing a brief tactile / sensory analysis. The model 01 represents a lower density of cells, has a lighter structure and a lower volume of material, also presented itself as the most flexible model. Model 02 represents intermediate density, slightly increasing the volume of material and weight. Model 03 has the highest density pattern, consequently, greater volume and weight, resulting in greater strength and rigidity of the part.

- Models 04 and 05 (See Figure 15 below) have a varied distribution pattern. Comparing the two models, model 04 represents a high density of cells highlighted in the corner with thick walls, this is a model that presented a greater volume of material, greater weight and greater rigidity and resistance. The model 05 , despite having a lower density in the center, the walls are quite thick, which makes it have less weight and volume than the model 04 . However, this represents a situation in which the structure needs greater reinforcement without increasing too much its weight and volume of material, achieving a balance between strength and lightness. 


\section{Composite study with bio-based materials}

This stage of the investigation aims to explore the potential of agave fibers as a reinforcement material in bioinspired composites. One of the materials that is being explored together with the fibers is PLA, as it is a biodegradable material and is very widespread in additive manufacturing and allows it to mix with other materials, and can be produced extruded in the form of filament. The research also aims to explore other possibilities of using bio-based resins, but which will not be addressed in this work.

This descriptive memorial presents and describes in a summarized way with illustrative images of the main stages of the material handling process and development of the composite made of PLA + Agave fibers. The fibers were crushed, then they were sent to carry out the separation and granulometry, obtaining fibers with different sizes. The most suitable fibers were selected for the purposes of investigation and manipulation of composites. Silicone molds were used to mold the specimens, they were all machined and selected for analysis. The compound was manipulated in the form of test pieces with different compositions of PLA and agave fibers. The sample specimens should be solid and were molded with a uniform rectangular cross section.

The sieving process consists of using several sieves with gradation in the granulometry and in this way it is possible to obtain various dimensions. 7 gradual sizes were obtained. $45 \mu$ (microns); $75 \mu ; 106 \mu ; 250 \mu ; 425 \mu ; 600 \mu ; 850 \mu$. Which were analyzed and evaluated which are the most appropriate for experimentation. The $45 \mu$ and $75 \mu$ are very fine powders, the $106 \mu$ is already visible to the naked eye with small fibers, the $250 \mu$ and onwards is already in the shape of larger fibers, not being suitable for the development of filaments with diameters of $0,75 \mathrm{~mm}$, the finer particles being ideal.
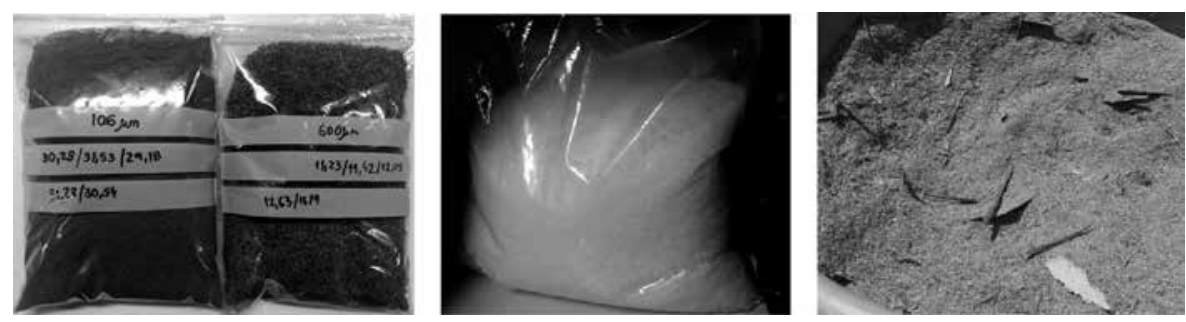

Figure 16. Crushed fibers without separation; Selected fibers for sample development; PLA pellets. Source: Authors (2021). 
The selected fibers were: $106 \mu$ and $600 \mu$, one smaller and one larger, the fibers can have different applications according to their formal configuration, in powder or in microfibers. With these selected, 04 different compositions were developed in the mixture with the PLA: which were added amounts of 5 and $10 \%$ of fiber in the compositions. Compositions: $600 \mu 5 \% ; 600 \mu 10 \% ; 106 \mu 5 \% ; 106 \mu 10 \%$

3D Printing Monofilament PLA pellets - General Use Grade - from Natureworks were used. This material has a multipurpose extrusion grade that results in $3 \mathrm{D}$ printing monofilament with excellent printing characteristics. This material is suitable for $3 \mathrm{D}$ printing using many different types of printers and for a wide range of printing applications.

\section{Preparation of specimens with composite material using PLA + Agave fibers}

The materials are weighed and mixed according to defined percentages. Then the PLA pellets are deposited in a refractory to be heated and then mixed with the fibers and then melted in the silicone molds. After cooling, they are machined and the burrs are removed (See Figure 17).

$600 \mu 5 \% \quad 600 \mu 10 \% \quad 106 \mu 5 \% 106 \mu 10 \%$

\section{Preparation of the composite for the filament extruder}

A survey was carried out to get to know different models of extruder machines, to carry out the development of the filament with the designed bioinspired composite. PLA extrusion tests were performed for greater interaction with the definition of temperature variables and obtaining the correct filament thickness, these parameters will be redefined when starting the tests with the PLA composite reinforced with agave fibers. The composite must first be made into finer pieces, then pass through the crusher, then separate the particle size evenly and then feed the extruder funnel with the prepared material, so that no clogging occurs and a homogeneous filament is obtained. This is a work in progress, and to date the filament has not yet been produced, this is the stage that continues the process of producing the filament (See Figure 18).

After the production of the filament, printing tests with the material obtained will begin. Models of the bio-inspired voronoi structures that were parameterized in Grasshopper will be printed. The structures will then be manipulated by changing the sizes of the plates, as well as the density of the cells and thickness of the walls, for example. And carrying out alternative modeling based on Agave's light and resistant strategy regarding the behavior of the structure printed with the fiber itself. The plates printed by FDM with the filament will allow us to carry out diverse analyzes: sensory, materials, density, weight, flexibility, rigidity, texture, finish, etc. 


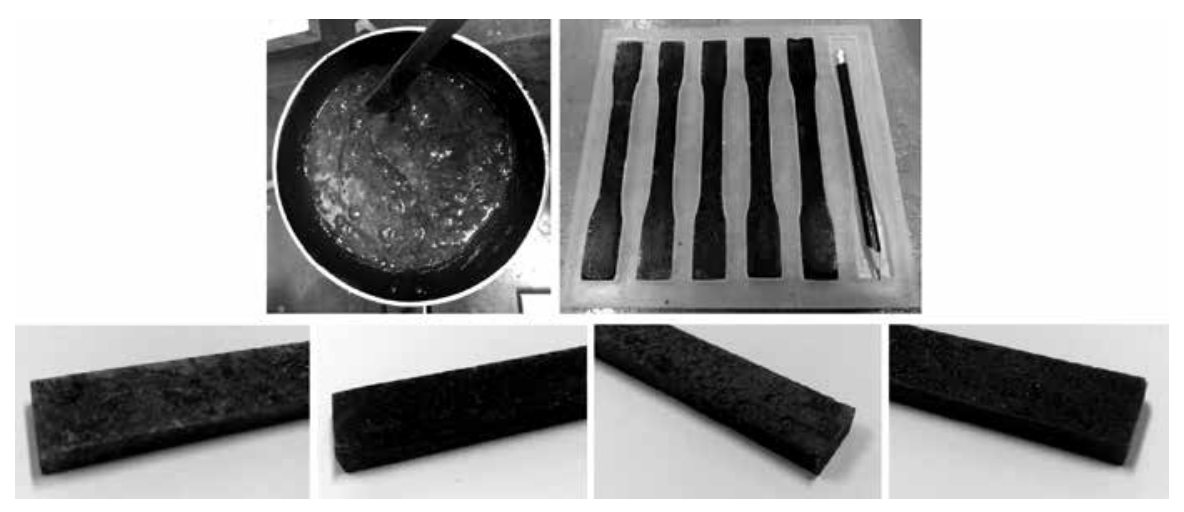

17
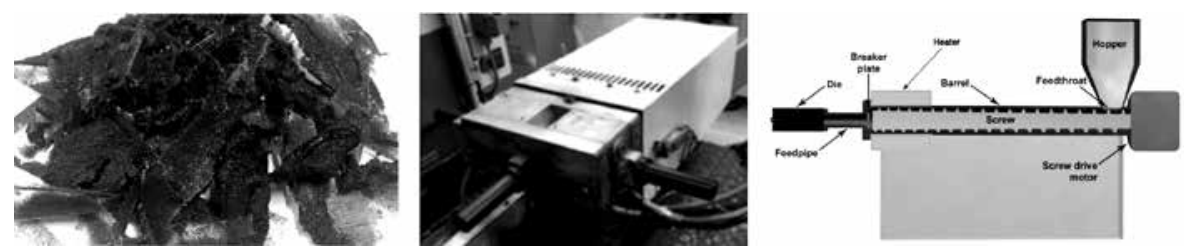

18

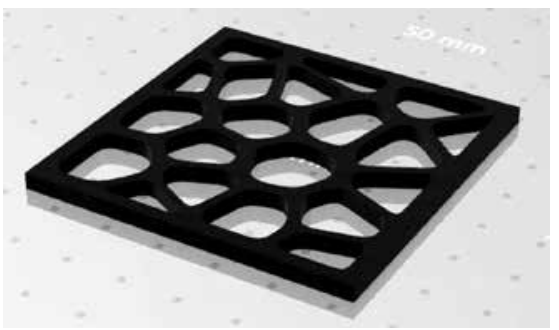

Figure 17. Manipulation of the bioinspired composite material with the developed specimens. Source: Authors, (2020). Figure 18. Fiber + PLA composite to be extruded; Extruder to be used; Different parts of extruder. Sources: Authors (2021); Choton et al. (2020). Figure 19. Simulation of the impression with the bioinspired composite. Source: Authors (2021).

19

These next printed models can also be used to produce silicone molds and to fuse parts with different composites, allowing experimentation with other bioinspired materials with different properties, such as rigid, flexible and expanded castor resins; pine resin and bio-based epoxy resins. Figure 19 represents the simulation of printing with bioinspired material in the same color as the composite manipulated with Agave and PLA. 


\section{Conclusion}

Inspiration with nature is an important aspect in design and architecture. It was verified the importance of designing biomimetic structures based on the patterns of biological structures, in addition to the foundation in plant anatomy and the study of Agave, with a focus on the types of cells present, their configuration, shape, and material composition. According to Novak (2015), the contemporary line of thought is to understand the processes that occur in nature and to describe them in an appropriate way, in order to apply these models in technology. The development of digital tools currently used in design and architecture has enabled the portability of projects found in nature for the spatial and structural conformation of sustainable artifacts.

This ongoing $\mathrm{PhD}$ research attempts to reflect on the questions and questions that can be raised about light constructions: How to design more efficient and sustainable bioinspired structures? Which structural configuration best meets the requirements for lightness and strength? Are bioinspired structures liable to be applied to artifacts? Currently, there are digital printers that work by adding processes. With the existing technology, one can focus on the development of a new bioinspired material, which could be a positive alternative for printing light, resistant and biodegradable bioinspired artifacts, reducing the impacts on the environment.

When natural model strategies are incorporated into digital manufacturing processes, they present a great potential for innovation in sustainability, which makes us think of applications for different sectors and artifacts. Information on the cellular anatomy of Agave contributed greatly to achieving an optimum in the design of light and resistant structures combined with the use of sustainable materials. Based on these data, the choice of agave as a natural system and source of structural and material bioinspiration is justified in line with the principles of biomimetics and sustainability.

\section{References}

Akos, G. \& Parsons, R. (2014). Grasshopper primer $3^{\circ}$ ed. Studio Mode, LLC.

Aurenhammer, F. (1991). Voronoi Diagrams - A Survey of a Fundamental Geometric Data Structure. Institute fur Informationsverarbeitung Technische Universitat Graz, Schiet stattgasse 4a, Austria.

Araújo, R. (2015). Biomimética e artefatos para ambientes aquáticos - estratégias de leveza e resistência inspiradas na estrutura celular do agave. Ed. Novas Edições Acadêmicas, Omni Scriptum Publishing Group - Beau Bassin.

Ashby, M.; Johnson, K. (2011). Materiais e Design: Arte e Ciências da Seleção de Materiais do Design do Produto. 2. ed. Rio de Janeiro: Campus.

Baumeister, D. (2014). Biomimicry Resource Handbook. A seed of Best Practices. Ed. Biomimicry 3.8 - Missoula, Montana.

Benyus, J. (2003) Biomimética: Inovação inspirada pela natureza. Ed. Pensamento-Cultrix. 
Bhushan, B.(2009). Lessons from nature - an overview. Disponível em: http://rsta.royal societypublishing.org

Byrne, G.; Dimitrov, D.; Monostori, L.; Teti, R.; Houten, F.; Wertheim, R. (2018). Biologicalisation: Biological Transformation in Manufacturing. CIRP Journal of Manufacturing Science and Technology. Volume 21, May 2018, Pages 1-32. https://doi.org/10.1016/j. cirpj.2018.03.003

Callister, W. (2000). Ciência e engenharia dos materiais - Uma introdução. 5ed. Rio de Janeiro, LTC Ed.

Carneiro, J. (2017). Caracterização de acessos de sisal usando descritores da planta e da fibra. Tese doutorado. Programa de pós-graduação em recursos genéticos vegetais - Universidade Estadual de Feira de Santana - BA.

Cohen, Y. \& Reich, Y. (2016). Biomimetic Design Method for Innovation and Sustainability. Springer International Publishing - doi:10.1007/978-3-319-33997-9 - Switzerland.

Damodaram, R. (2018). Bio-Mimetic Design With 3d Printable Composites. Thesis Master of Science. South Dakota State University.

Daya, T. (2017). Facilitating Sustainable Material Decisions: A Case Study of 3D Printing Materials. Tese de doutorado. UC Berkeley Electronic Theses and Dissertations.

Gleich, A.; Pade, C.; Petschow, U.; Pissarskoi, E. (2002). Potentials and Trends in Biomimetics. Springer. New York.

Martin, A., Martins. M., Mattoso, L., Silva, O. (2009). Caracterização química e estrutural de fibra de sisal da variedade Agave Sisalana - Polímeros: Ciência e Tecnologia, vol. 19, $n^{\circ} 1$, p. 40-46, SP

Müller, R.; Abaid, N.; Boreyko, J. B.; Fowlkes, C.; Goel, A. K.; Grimm, C.; Jung, S.; Kennedy, B.; Murphy, C.; Cushing, N. D.; Han, J.(2018). Biodiversifying Bioinspiration. Bioinspiration \& Biomimetics - IOP Science, Volume 13, Number 5.

Mwaikambo, L. \& Ansell, M. (2002). Chemical modification of hemp, sisal, jute, and kapok fibers by alkalization. Journal of Applied Polymer Science, 84(12), 2222-2234. https:// doi.org/10.1002/app.10460

Nowak, A. (2015). Application of Voronoi diagrams in contemporary architecture and town planning - Challenges of Modern Technology. vol. 6, no. 2. 30-34.

Oxman, N.; Ortiz, C.; Gramazio, F.; Kohler, M. (2015). Computer-Aided Design. Elsevier, Volume 60.

Pauw I. (2015). Nature-Inspired Design - Strategies for Sustainable Product Development. PhD thesis Delft University of Technology, Delft, the Netherlands.

Rael, R. \& Fratello, V. (2018). Printing Architecture - Innovate Recipes for 3D printing - of emerging objects. Princeton Architectural Press; Illustrated edition.

Rattes, R. (2015). Biomimética aplicada ao Metadesign: Geração de Máquinas Abstratas com base no estudo do Mandacaru. Dissertação para obtenção de Grau de Mestre em Design. Universidade Federal de Pernambuco. Recife.

Sapuan, S.M.; et al. (2006). Mechanical properties of woven banana fiber reinforced epoxy composites. Mat. Des., v. 27, pag. 689-693.

Schumacher, P. (2021 Maio) Patrik Schumacher on parametricism - 'Let the style wars begin' 2010. https://www.architectsjournal.co.uk/practice/culture/patrik-schumacher-on-para metricism-let-the-style-wars-begin 
Soares, T. \& Arruda, A. (2018). Novas estratégias da biomimética: as analogias no biodesign e na bioarquitetura. Mix Sustentável. Florianópolis. v.4 - n.1 - p.73-82 - março.

Taiz, L.; Zeiger, E. (2004). Fisiologia vegetal. Porto Alegre: Artmed

Tedeschi, A. (2014). AAD Algorithms-Aided Design. Parametric strategies using grasshopper. ed. Le Penseur.

Wimmer, R.; Koddenberg, T.; Steyrer, B. (2015). 3D Printing and Wood. International Conference Wood Science and Engineering in the Third Millennium - ICWS, DOI: 10.13140/RG.2.1.2483.6563

Resumen: La bioinspiración en las estrategias de diseño de la naturaleza alineadas con la fabricación digital, tienen gran relevancia para la resolución de problemas con un enfoque en la aplicación sistemática de información biológica para la emulación de elementos naturales. Actualmente, las posibilidades están dadas por las últimas tecnologías, sistemas de producción y el desarrollo de nuevas estructuras y materiales. Esta investigación explora la investigación de la biología, el uso de la computación paramétrica y la fabricación digital, incluyendo experimentos con materiales sostenibles como dimensiones inseparables del diseño bioinspirado. Las fibras de Agave Sisalana tienen excelentes propiedades de ligereza y resistencia proporcionadas por el patrón estructural de las paredes celulares y sus propiedades materiales. Presentarse como un sistema natural de inspiración biomimética y experimentación de materiales bioinspirados.

Palabras clave: Biomimetismo - Bioinspiración - Agave - Diseño paramétrico - Fabricación digital - Saltamontes - Diseño de materiales - Fibras naturales - Materiales bioinspirados - Impresión 3D

Resumo: A bioinspiração nas estratégias de design da natureza alinhadas com a fabricação digital, tem grande relevância para a solução de problemas com foco na aplicação sistemática de informações biológicas para a emulação de elementos naturais. Atualmente, as possibilidades são dadas pelas mais recentes tecnologias, sistemas de produção e o desenvolvimento de novas estruturas e materiais. Esta pesquisa explora a investigação da biologia, o uso da computação paramétrica e a fabricação digital, incluindo experimentos com materiais sustentáveis como dimensões inseparáveis do design bioinspirado. As fibras do Agave Sisalana apresentam excelentes propriedades de leveza e resistência proporcionadas pelo padrão estrutural das paredes celulares e suas propriedades materiais. Sendo apresentado como um sistema natural de inspiração biomimética e experimentação de materiais bioinspirados.

Palavras chave: Biomimética - Bioinspiração - Agave - Design paramétrico - Fabricação digital - Gafanhoto - Design de materiais - Fibras naturais - Materiais bioinspirados - Impressão 3D 